Open Access

\title{
Propranolol reduces viability and induces apoptosis in hemangioblastoma cells from von Hippel-Lindau patients
}

Virginia Albiñana ${ }^{1}$, Karina Villar Gómez de las Heras², Gemma Serrano-Heras ${ }^{3}$, Tomás Segura ${ }^{3}$, Ana Belén Perona-Moratalla ${ }^{3}$, Mercedes Mota-Pérez ${ }^{2}$, José María de Campos ${ }^{5^{\wedge}}$ and Luisa María Botella $a^{1,4^{*}}$

\begin{abstract}
Background: Von Hippel-Lindau (VHL) disease is a rare oncological disease with an incidence of 1:36,000, and is characterized by the growth of different types of tumors: hemangioblastomas in the central nervous system (CNS) and retina, renal carcinoma, pheochromocytomas, pancreatic serous cystadenoma, and endolymphatic sac tumors. These tumors do not express VHL protein ( $\mathrm{pVHL}$ ). pVHL ubiquitinates hypoxia inducible factor (HIF) protein for degradation by the proteasome; in the absence of VHL, HIF translocates to the nucleus to activate the expression of its target genes. Targeting VHL-derived tumors with drugs that have reduced side effects is urgent to avoid repeat CNS surgeries. Recent reports have shown that propranolol, a $\beta$-blocker used for the treatment of hypertension and other cardiac and neurological diseases, is the best option for infantile hemangioma (IH). Propranolol could be an efficient treatment to control hemangioblastoma growth in VHL disease because of its antiangiogenic effects demonstrated in $\mathrm{H}$ and the hypothetical impact on HIF levels.
\end{abstract}

Methods: HeLa 9X (HRE) hypoxia responsive element cell line and primary hemangioblastoma-derived cells were subjected to propranolol treatment and cell viability and apoptosis were evaluated. HIF1-a and Hif-2a expression after propranolol treatment was analyzed by western blotting. Quantitative PCR was performed to study the mRNA expression of HIF target genes. Vascular endothelial growth factor (VEGF) was measured in culture supernatants by immunoassay.

Results: Propranolol downregulated HIF-dependent transcription in HeLa 9XHRE cells. Under hypoxic conditions, propranolol decreased the expression of HIF target genes in hemangioblastoma cells, which stopped proliferating and died following long-term treatment. These results suggests that propranolol treatment promoted reduced HIF protein expression and corresponding downregulation of HIF target genes, and inhibited cell proliferation in parallel with induction of cell death by apoptosis.

Conclusions: Our results suggest that propranolol could reduce the growth of HIF-dependent tumors and may thus be a promising treatment to delay surgery in VHL patients.

Keywords: von Hippel-Lindau disease (VHL), pVHL, Hypoxia inducible factor, hemangioblastoma, CNS tumors, Propranolol

\footnotetext{
* Correspondence: cibluisa@cib.csic.es

Deceased

${ }^{1}$ Centro de Investigaciones Biológicas, CSIC, Madrid, Spain

${ }^{4}$ Centro de Investigación Biomédica en Red de Enfermedades Raras

(CIBERER), Madrid, Spain

Full list of author information is available at the end of the article
}

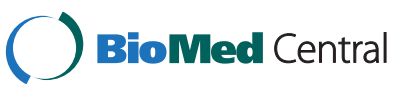

(c) 2015 Albiñana et al. Open Access This article is distributed under the terms of the Creative Commons Attribution 4.0 International License (http://creativecommons.org/licenses/by/4.0/), which permits unrestricted use, distribution, and reproduction in any medium, provided you give appropriate credit to the original author(s) and the source, provide a link to the Creative Commons license, and indicate if changes were made. The Creative Commons Public Domain Dedication waiver (http://creativecommons.org/publicdomain/zero/1.0/) applies to the data made available in this article, unless otherwise stated. 


\section{Background}

Von Hippel-Lindau (VHL) disease is a rare type of phacomatosis with an incidence of 1 per 36,000 individuals in the general population $[1,2]$. The clinical manifestations include multiple benign and malignant tumors that appear throughout the lifespan of the patient. The most frequent tumors are hemangioblastomas (HB) of the central nervous system (CNS) and retina, and renal cell carcinoma [3-6]. In addition, pheochromocytomas, pancreatic serous cystadenoma, endolymphatic sac tumors and papillary cystadenomas are associated with the disease.

VHL disease is an inherited entity, with autosomal dominant transmission. Patients are heterozygous for mutations in $V H L$, a tumor suppressor gene located on the short arm of chromosome 3 (3p25-p26). Tumors develop in patients who have a mutated copy of $V H L$ at birth following loss of the wild-type allele (loss of heterozygosity) [7]. Thus, the tumors of these patients either do not express VHL protein (pVHL) or the mutated form is not functional. pVHL binds to and ubiquitinates HIF- $1 \alpha$ and HIF- $2 \alpha$ to target them to the proteasome for degradation. Therefore, in the absence of functional pVHL, HIF accumulates within the cytoplasm and translocates to the nucleus to trigger the hypoxia program by targeting hypoxia responsive genes [8]. HIF- $1 \alpha$ and HIF- $2 \alpha$ are involved in cell proliferation, angiogenesis, extracellular matrix degradation, vascular tone, and erythropoiesis, among other processes. All HIF target genes are normally silenced in normoxia. pVHL cannot bind HIF in hypoxic conditions, since prolylhydroxylases cannot hydroxylate specific proline residues of HIF. In these circumstances, HIF accumulates and translocates to the nucleus. Therefore, cells from VHL tumors have a constitutively active HIF program due to the absence of functional pVHL.

Thus far, the therapeutic options for VHL patients are derived from surgery $[9,10]$. The systemic therapy used for metastatic cancers has shown limited response in VHL pancreatic and renal tumors, while CNS tumors do not respond at all. Therefore, the lack of therapies for diffuse or recurrent disease means there is an urgent requirement for effective drugs with reduced side effects for VHL patients, especially those that halt the progression of tumors and subsequently delay surgical treatment. Some previous studies have shown that propranolol, a $\beta$-blocker used for the treatment of arrhythmia, hypertension, migraines, and other cardiac and neurological diseases, is also the best option for the treatment of infantile hemangioma (IH) [11-15]. IH is the most frequent vascular benign tumor in newborns. In the last few years, propranolol has become the choice treatment for IH over surgery, with a long list of publications supporting its success. In relation to this, our group has demonstrated that endothelial cells treated with propranolol showed decreased expression of the pro-angiogenic proteins endoglin and ALK1, which are
HIF-1 $\alpha$ targets [16]. Although the precise mechanism of action of propranolol is unclear, upon blocking $\beta$ adrenergic receptors, propranolol leads to vasoconstriction (reducing the blood flow), apoptosis induction, and inhibition of angiogenic HIF target genes such as vascular endothelial growth factor (VEGF), fibroblast growth factor $(F G F)$ or metalloproteases (MMPs).

Therefore, these results led us to consider the hypothesis that propranolol could be an efficient treatment for hemangioblastomas through inhibition of HIF in highly vascularized tumors in which HIF is constitutively expressed.

\section{Methods \\ Cell culture}

HeLa 9XHRE cells were stably transfected with a HREluc reporter carrying nine copies in tandem of the hypoxia responsive element (HRE) followed by luciferase gene, and were cultured in DMEM (Dulbecco's Modified Eagle Medium, Gibco, Grand Island, NY, USA) supplemented with $10 \%$ fetal bovine serum (FBS; Gibco), $2 \mathrm{mM} \mathrm{L}$-glutamine and $100 \mathrm{U} / \mathrm{ml}$ penicillin/streptomycin (Gibco). To induce hypoxic conditions, HeLa cells were cultured either with $100 \mu \mathrm{M}$ desferrioxamine (DFO) (chemical hypoxia) or incubated in a hypoxic chamber (Billups-Rothemberg, Inc, Del Mar, CA) in $1 \%$ oxygen, $5 \% \mathrm{CO}_{2}$ and $94 \% \mathrm{~N}_{2}$, for $24 \mathrm{~h}$.

Primary cultures of CNS hemangioblastoma were obtained according to the previously novel protocol designed by Serrano-Heras and scientific collaborators from General University Hospital of Albacete, Spain (Manuscript in preparation). Between March 2013 and march 2014 clinical samples from 4 patients ( 3 men and 1 woman, mean range $31.5 \pm 15.6$ years, and range: 13-45) diagnosed of Von Hippel-Lindau disease were taken collected from the Neurosurgery department at "Fundación Jiménez Díaz", Universitary Hospital, Spain. Prior informed consent written forms were obtained from all patients. All procedures had been previously approved by the Ethics Committee in accordance with general accepted guidelines for human samples. The collected fresh tissue from the excess of resected hemangioblastoma was placed in sterilized tubes containing ice-cold Earle's Balanced Salt Solution (EBSS, Gibco). Tumor samples were washed several times with PBS, and cut into $1 \mathrm{~mm} 3$ pieces. Tissue pieces were transferred with sterile tweezers to clean cell culture dishes (Sarstedt, Germany) and subjected to enzymatic digestion with equal amount of collagenase I and dispase II to a final concentration of $1 \mathrm{mg} / \mathrm{m}$ in EBSS, for $45 \mathrm{~min}$ at $37^{\circ} \mathrm{C}$. After that, the pieces were completely disaggregated by gently pipetting and digested for 15 min with trypsin at $37^{\circ} \mathrm{C}$. Then, minced samples were centrifuged, cell pellets were suspended in growth medium (RPMI 1640 (Gibco) supplemented with $20 \%$ fetal bovine serum, $1 \%$ Pen/Strep 
and $4 \mathrm{mM}$ of glutamine), and incubated at $37^{\circ} \mathrm{C}$. Medium was replaced every $72 \mathrm{~h}$ until the cultures were confluent.

Furthermore, Flow Cytometry was performed for cell characterization. The analysis showed that cultures were composed of stromal cells (30-50\% CD99+ cells), endothelial cells (15-25\% CD34+ cells), and pericytes (30-40\% $\mathrm{NG} 2+$ cells). The experiments were performed in all types of cells composing the hemangioblastoma. A total of four hemangioblastomas from different patients were assayed in culture, with the following localization: HB2, spinal bulb; HB3, temporal lobe; HB7, spinal cord; HB11, temporal lobe.

\section{Real-time RT-PCR}

Total cellular RNA was extracted from hemangioblastoma cells using a Nucleo Spin RNA kit (Macherey-Nagel, Düren, Germany). One microgram of total RNA was reverse-transcribed in a final volume of $20 \mu \mathrm{l}$ with the First Strand cDNA Synthesis Kit (Roche, Mannheim, Germany) using random primers. SYBR Green PCR system (BioRad, Hercules, CA, USA) was used to carry out real-time PCR with an iQ5 system. The sequences of the oligonucleotides used corresponded to HIF- $1 \alpha$ and $-2 \alpha$ target genes, as follows: VEGF forward: 5'ATCTGAGCAGGGCGACAGC-3' and reverse 5'-ACTCCCTGTGGTGCAGTCA-3'; EPO forward 5'-TGTTTTCGCACCTACCATCA-3' and reverse 5'AAGTCACAGCTTGCCACCT-3'; and SOX2 forward 5'-GGGGGAATGGACCTTGTATAG-3' and reverse 5'CGCTCCACCAACTAAGAACG-3'. As an internal control, mRNA levels of $18 S$ were measured using the following primers: forward 5'-CTCAACACGGGAAAC CTCAC-3' and reverse 5'-CGCTCCACCAACTAAGAA CG-3'. Amplicons were detected using an iQ5 system (BioRad). The samples were used in triplicate and the experiment was repeated twice.

\section{Western blot analysis}

Cells were lysed on ice for $30 \mathrm{~min}$ in TNE buffer (Tris $50 \mathrm{mM} \mathrm{NaCl} 150$ mM-EDTA 1 mM 0.5 \% Triton X100) supplemented with protease inhibitors (Complete Roche Diagnostics) and lactacystin as a specific proteasome inhibitor to preserve HIF. Lysates were centrifuged at 14,000 $\times g$ for $5 \mathrm{~min}$. Similar amounts of proteins from aliquots of cleared cell lysates were boiled in SDS sample buffer and analyzed by $10 \%$ SDS-PAGE under non-reducing conditions. Proteins from gels were electrotransferred to nitrocellulose membranes followed by immunodetection with anti-HIF1 $\alpha$ (BD, Bedford, MA, USA), anti-HIF- $2 \alpha$ (NOVUS, Oxon, UK) and anti- $\gamma$-tubulin (Sigma, St.Louis, MO, USA) antibodies at the dilution recommended by the manufacturer. Secondary antibodies were horseradish peroxidase conjugates from Dako (Glostrup, Denmark). Membranes were developed by chemiluminescence
(SuperSignal West Pico Chemiluminescent Substrate, Thermo Scientific, Rockford, IL, USA).

\section{Luminescent cell viability assay}

The viability of hemangioblastoma and HeLa 9X HRE cells was measured with a CellTiter-Glo Luminescent Cell Viability Assay (Promega, Madison, WI, USA). This is a homogeneous method to determine the number of viable cells in culture based on quantitation of the ATP present, which signals the presence of metabolically active cells. A total of 10,000 cells were plated in 96-well plates and cultured for $24 \mathrm{~h}$ and $48 \mathrm{~h}$ with propranolol $(50 \mu \mathrm{M}$ and $100 \mu \mathrm{M})$ in $100 \mu \mathrm{l}$ of medium. After treatment, plates were equilibrated to room temperature for $30 \mathrm{~min}$ before the addition of $100 \mu \mathrm{l}$ of Cell Titer-Glo reagent (Lysis buffer, Ultra-Glo Recombinant Luciferase, Luciferine and $\mathrm{Mg}^{2+}$ ). Cell lysis was induced in an orbital shaker for $2 \mathrm{~min}$, and then plates were incubated at room temperature for $10 \mathrm{~min}$ to stabilize the luminescent signal. Luminescence was measured using a Glomax Multidetection System (Promega).

\section{Caspase activation assay}

The Caspase-Glo 3/7 Assay (Promega) is a luminescent assay that measures caspase- 3 and caspase- 7 activity using a luminogenic caspase-3/7 substrate that contains the tetrapeptide sequence DEVD in a reagent optimized for caspase activity, luciferase activity and cell lysis. Luminescence is proportional to the amount of caspase activity present. A total of 10,000 hemangioblastoma cells were plated in 96-well plates and cultured for $24 \mathrm{~h}$ and $48 \mathrm{~h}$ with propranolol $(50 \mu \mathrm{M}$ and $100 \mu \mathrm{M}$ ) in $100 \mu \mathrm{l}$ of medium. After treatment, plates were equilibrated to room temperature for $30 \mathrm{~min}$ before the addition of $100 \mu \mathrm{l}$ of Caspase Glo 3/7 Reagent (lysis buffer, Ultra-Glo Recombinant Luciferase, DEVD-aminoluciferine and $\left.\mathrm{Mg}^{2+}\right)$. Cell lysis was induced by shaking for $30 \mathrm{~s}$ (300 rpm), and then plates were incubated at room temperature for $2 \mathrm{~h}$. Luminescence was measured using a Glomax Multidetection System (Promega).

\section{VEGF determination in plasma}

A Quantikine Human VEGF ELISA kit from R\&D Systems (Abingdon, UK) was used to quantitatively determine human VEGF-A concentration in supernatants of hemangioblastoma culture cells treated with propranolol at different doses.

\section{Statistics}

Data represent mean \pm SD. Differences in mean values were analyzed using the Student's $t$-test. $P$-values of $<0.05$ were considered to be statistically significant; 
statistically significant values are marked with asterisks $\left({ }^{*} P<0.05 ; * * P<0.01 ;{ }^{* * *} P<0.005\right)$.

\section{Results}

\section{Propranolol downregulates HIF-dependent transcription} in 9XHRE HeLa cells

HeLa cells stably transfected with HRE-luc reporter were used to measure HIF-dependent transcription (Fig. 1a). Hypoxia activation was measured quantitatively by a luminometry assay under hypoxic conditions. When HeLa cells were subjected to chemical hypoxia $(100 \mu \mathrm{M}$ DFO), a marked increase in luciferase units, over normoxic conditions, of up to 3.5 fold was detected. However, treatment of the cells in hypoxic conditions with 50 and $100 \mu \mathrm{M}$ propranolol counteracted the hypoxic stimulation of HeLa 9XHRE cells, as shown by a decrease in luciferase activity (Fig. 1b). The results were statistically significant in all cases, with the exception of those obtained under normoxia and for treatment with $50 \mu \mathrm{M}$ propranolol $(P<0.005)$. Culture of cells in a hypoxic chamber $\left(1 \% \mathrm{O}_{2}\right)$ with or without propranolol yielded essentially the same results as with DFO (data not shown).

\section{Propranolol decreases the expression of HIF target genes} in hemangioblastoma cells

Next, we explored the effects of propranolol treatment of hemangioblastoma cells over HIF targets. Thus, the expression of genes transcriptionally regulated by HIF-

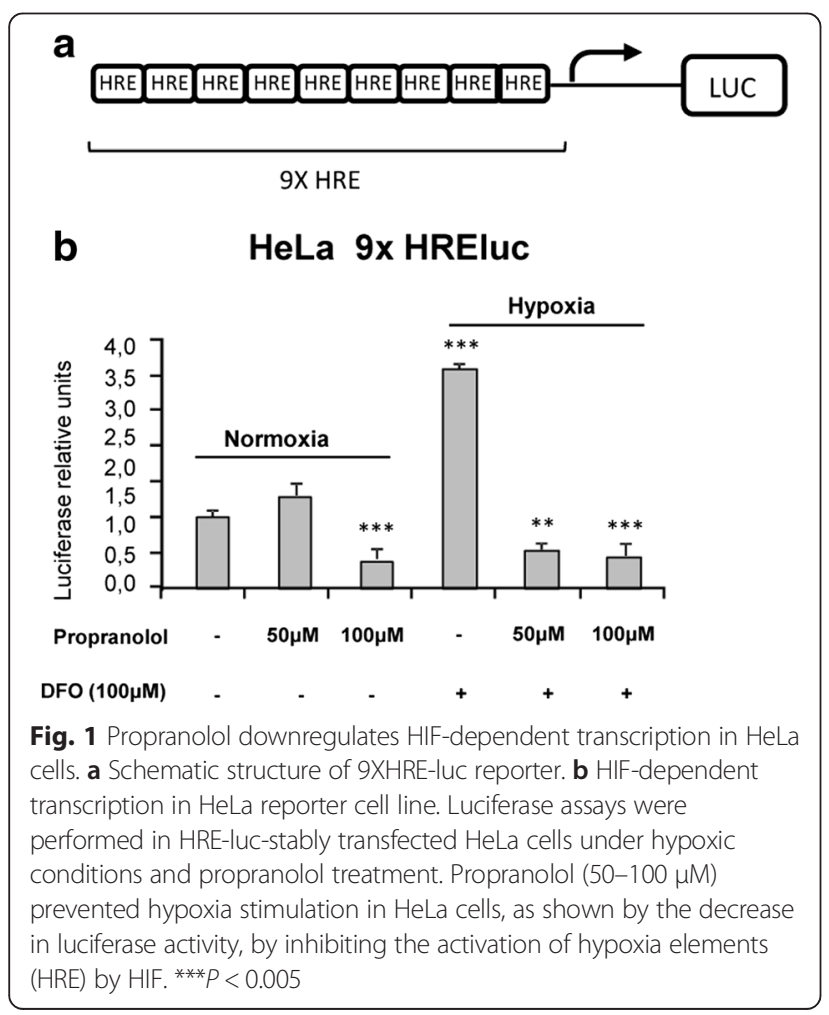

$1 \alpha$, such as VEGF and EPO (erythropoietin), and HIF$2 \alpha$, such as SOX2 (SRY-related HMG BOX) was studied by quantitative RT-PCR. As shown in Fig. 2a, the levels of transcripts of all these genes were significantly decreased by $40-60 \%$ from a dose of $50 \mu \mathrm{M}$. The levels of EPO and SOX2 were reduced in a dose-dependent manner; at $100 \mu \mathrm{M}$ propranolol, the level of the different mRNAs was about $40 \%$ of the controls. These results were observed in all four hemangioblastomas samples. The results agree with a lower transcription level of HIF target genes. Notably, VEGF and EPO are HIF- $1 \alpha$ targets involved in angiogenesis and oxygen supply to cells, while SOX2 is a transcriptional target of HIF- $2 \alpha$ and is a stemness target implicated in the undifferentiated nature of the mesenchymal component predominant in hemangioblastomas [17-19].

$V E G F$, one of the main targets of HIF-1 $\alpha$, and a potent mediator of both angiogenesis and vasculogenesis, was also measured in the supernatants of two different hemangioblastoma samples cultured with and without propranolol. As observed in Fig. 2b, the levels of VEGF were decreased by treatment with $50 \mu \mathrm{M}$ propranolol, in agreement with the mRNA results (Fig. 2a).

\section{Propranolol affects the viability of tumor cells and induces cell death by apoptosis}

Albiñana et al. (2012) reported that propranolol induces apoptosis and decreases viability of human endothelial and EOMA cells (murine hemangioendothelioma endothelial cells) $[16,20]$. Viability of HeLa cells after DFO treatment (chemical hypoxia), with and without propranolol, was quantitatively measured using the CellTiter-Glo luminescent cell viability assay. As shown in Fig. 3a, propranolol treatment affected the viability of HeLa cells. On the other hand, when apoptosis was measured quantitatively with the Caspase-Glo 3/7 luminescent assay, it was found that propranolol reduces viability of HeLa cells through an increase in apoptosis by caspase $3 / 7$ activation. After $48 \mathrm{~h}$ propranolol treatment, cells stopped proliferating, and the increase in caspase activity promoted cell death (Fig. 3b).

Next, we used the same assays to check survival and apoptosis of hemangioblastoma cells after propranolol treatment for 24 and $48 \mathrm{~h}$. Figure 4 shows viability, caspase 3/7 activation, and the caspase activation/viability ratio in the four hemangioblastoma cultures from four different VHL patients; viability decreased with propranolol in a concentration- and time-dependent manner in almost all cases. Here, each hemangioblastoma represents a different culture from a different patient and different tumor, therefore there is wide variability, but we show in all cases that the response is qualitatively similar. The lowest viabilities were found after treatment with $100 \mu \mathrm{M}$ of propranolol for $48 \mathrm{~h}$. This decrease in 


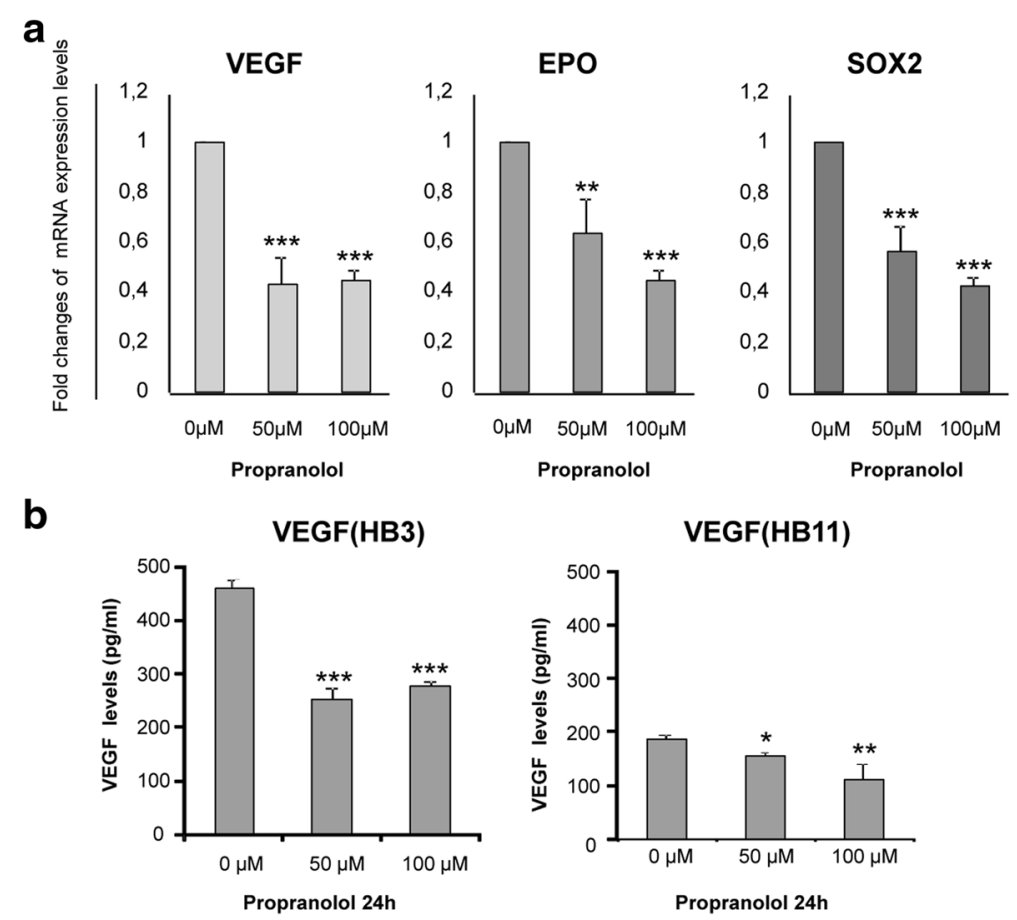

Fig. 2 Propranolol decreases the expression of HIF target genes in hemangioblastoma cells. a The transcription levels of HIF target genes, VEGF, EPO and SOX2, were compared with the endogenous control of $18 \mathrm{~S}$ ribosomal RNA. Propranolol treatment led to a dose-dependent decrease in mRNA expression as a consequence of the reduced expression of HIF targets. Differences were statistically significant according to the Student's t-test. ${ }^{*} P<0.05 ;{ }^{* *} P<0.01 ;{ }^{* * *} P<0.005$. b VEGF soluble levels were measured by ELISA assay in supernatants of hemangioblastoma cultures treated with propranolol. Soluble VEGF levels were decreased in propranolol-treated cells compared with untreated ones

viability can be explained by an increase in apoptosis through caspase $3 / 7$ activation, particularly at $100 \mu \mathrm{M}$ and after $48 \mathrm{~h}$ of treatment.

Given the previous results of viability reduction and apoptosis induction after propranolol treatment, we decided to subject hemangioblastoma cells to long-term propranolol treatment, starting with 50,000 cells per well, and recording images in a time course follow-up. As shown in Fig. 5, hemangioblastoma cells appeared to stop proliferating, and then an increase in cell death is detected since there were empty spaces in the plates.
The death, as explained by the previous results (Fig. 4), must be attributed to apoptosis. After 5 days $(96 \mathrm{~h})$ of continuous propranolol treatment, there were few cells remaining in the $100 \mu \mathrm{M}$ propranolol-treated cultures, with fewer than 5,000 cells with poor morphology, compared with 300,000 healthy cells in the untreated cultures. The remaining propranolol-treated cells, on the other hand, exhibited an atypical and apoptotic appearance.

Altogether, we can conclude that propranolol decreases the viability of tumor cells (HeLa and VHL-

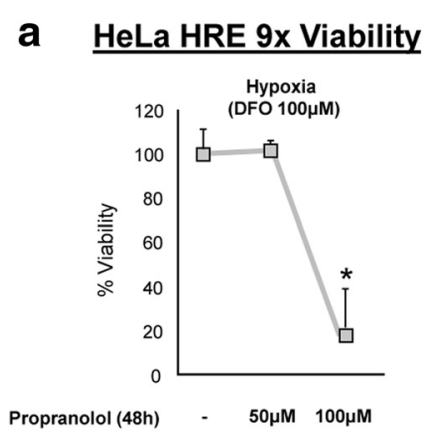

\section{b Caspase activity HeLa HRE 9x}

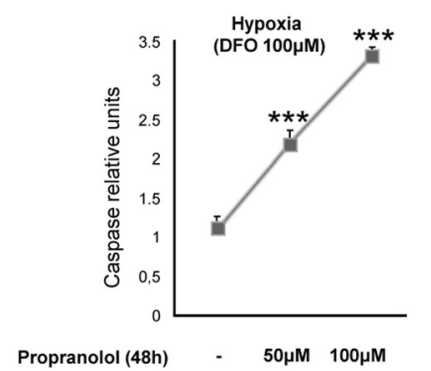

Fig. 3 Propranolol affects viability and caspase activation in HeLa cells. HeLa 9XHRE cells were cultured in the absence or presence of propranolol $(50 \mu \mathrm{M}$ or $100 \mu \mathrm{M})$. Viability was measured using a CellTiter-Glo assay (a), and apoptosis was measured using a Caspase-Glo 3/7 assay (b). The histograms show an increase in the activation of caspase $3 / 7$ and a reduction in cell viability 


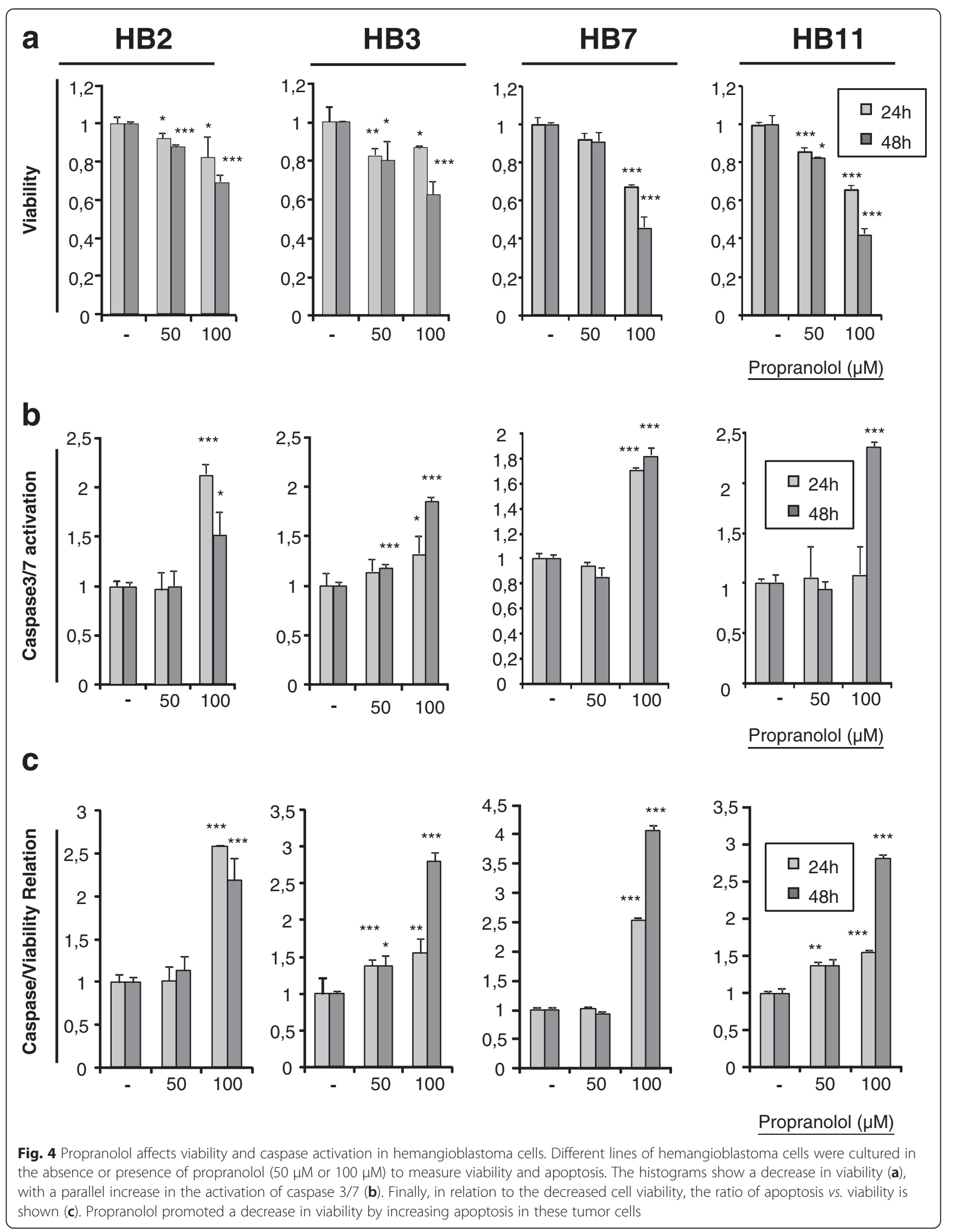




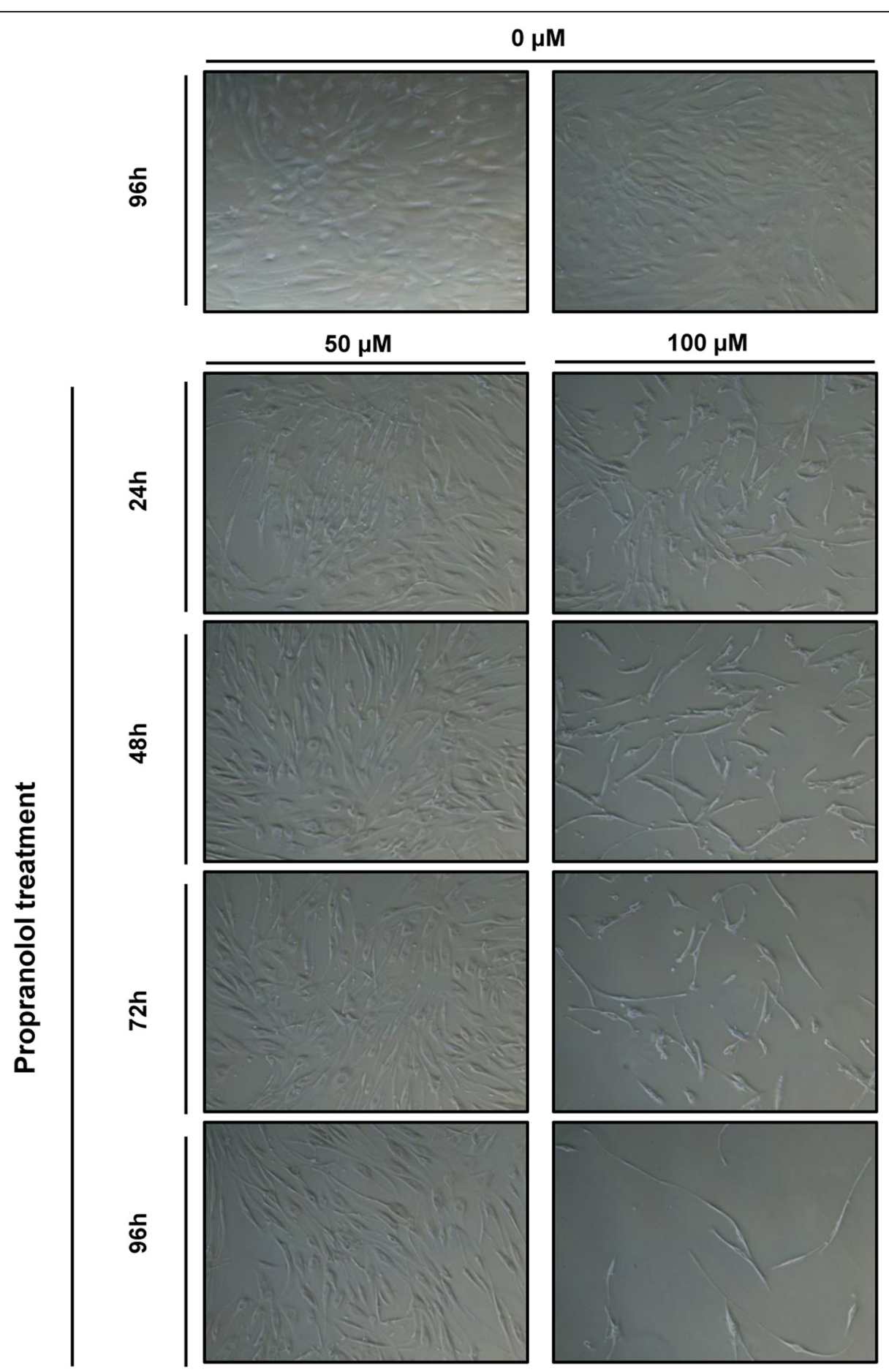

Fig. 5 Long-term propranolol treatment inhibits proliferation and promotes death of hemangioblastoma cells. Time course of propranolol treatment. Hemangioblastoma cells were treated at different doses $(50 \mu \mathrm{M}$ and $100 \mu \mathrm{M})$ and for varying lengths of time (from $24 \mathrm{~h}$ to $96 \mathrm{~h}$ ) with propranolol. Significant changes in morphology in treated cells were observed at $100 \mu \mathrm{M}$, while at $50 \mu \mathrm{M}$ the cells exhibited the same morphology as the control cells but with characteristic nucleoli. After $96 \mathrm{~h}$ with $100 \mu \mathrm{M}$ treatment, most cells had disappeared from the plate as a consequence of cell death by apoptosis (Magnification 40X) 
derived hemangioblastoma cells) by stopping proliferation and inducing cell death by apoptosis. This result would be compatible with the regression observed in $\mathrm{IH}$, and it would suggest that propranolol could delay the proliferation of hemangioblastomas in VHL patients.

Hemangioblastomas have a heterogeneous cell composition consisting of pericytes, stromal and endothelial cells. Propranolol affects all cell types. As a complementary result, Fig. 6 also supports the loss of migration and angiogenic activity of hemangioblastoma cells after propranolol treatment. In fact, propranolol treatment prevents the tubulogenesis displayed by the hemangioblastoma cells in matrigel. The endothelial/pericyte cells of hemangioblastomas display a typical network arrangement in special culture conditions such as matrigel. Thus, hemangioblastoma cells without propranolol treatment tend to build "tube-like structures of cells", while propranolol abrogates this manifestation of in vitro angiogenesis.

\section{Discussion}

Von Hippel-Lindau (VHL) is an autosomal dominant disease that results in many highly vascularized tumors disseminated over the body. VHL is an age-dependent and highly penetrant disease, and the more common manifestations include retinal and CNS hemangioblastomas, clear cell renal carcinomas, pheochromocytomas, and endolymphatic sac tumors of the middle ear [21, 22]. The mechanism for the pathogenesis of VHL disease is explained by the two-hit hypothesis [23]. One allele of $V H L$ is usually an inherited mutant copy while the second hit is acquired through somatic mutation or hypermethylation. Tissue microdissection has showed $V H L$ gene deletion in the stromal cells of hemangioblastomas [24], indicating that stromal cells are the true tumor cells derived from embryologically arrested hemangioblasts that are able to develop into hematopoietic and endothelial progenies under suitable conditions [2]. VHL is a complicated systemic disease with serious involvement throughout the entire body. Currently, there is no cure, nor successful therapeutic options, except surgery to remove the VHL tumors. Therefore, there is a need for drugs to target tumour growth to delay or remove the need for surgery.
VHL tumors express HIF1 $\alpha$ and HIF2 $\alpha$ in a constitutive manner $[17,18]$ since they lack functional pVHL. HIF is a transcription factor that can activate hundreds of target genes involved in angiogenesis, tumor formation, survival, invasion, and metabolism [25-27]. Given that tumors from VHL patients lack functional pVHL, HIF is constitutively expressed in normoxic conditions, as corroborated by the high levels of HIF detected in these tumors by western blotting (Fig. 7). This is in contrast with HeLa cells under normoxic conditions where there is no HIF protein, unless subjected to hypoxic conditions, as previously reported [28]. Hence, a drug targeting HIF, and thus the genes it regulates, would be the ideal strategy to delay VHL tumor progression.

It has been suggested that propranolol may act through different ways, including vasoconstriction, as an antiangiogenic inhibiting VEGF production, and as a proapoptotic drug leading to cell apoptosis [11, 20, 29, 30]. However, its potential therapeutic benefits in different vascular anomalies remain to be explored.

Based on previous results of propranolol efficiency for IH treatment [12-15], and our own results showing that propranolol acts as antiangiogenic in endothelial cells by decreasing transcription levels of proangiogenic factors such as endoglin and ALK1 [16], we hypothesized that propranolol could act by decreasing HIF levels and therefore downregulating the HIF target program. As a putative side effect of propranolol treatment, concerns about long-term neurodevelopmental or cognitive effects of propranolol have recently arisen after a study by Langley and Pope [31]. These authors argue that propranolol can cross the blood-brain barrier and can cause sleep and memory disturbances, as demonstrated by decreased specific memory functions in adults. This work was commented upon by Tozzi [32] in a letter to the Editor, and Léauté-Labrèze et al. responded [33] in the same issue of the journal. The reply is supported, first of all, by the lack of adverse events in children treated with propranolol. In fact, the rates of neurodevelopmental defects or delay observed among 272 propranolol-treated children from 2008 to 2013 seem to be within the range observed in the normal population.

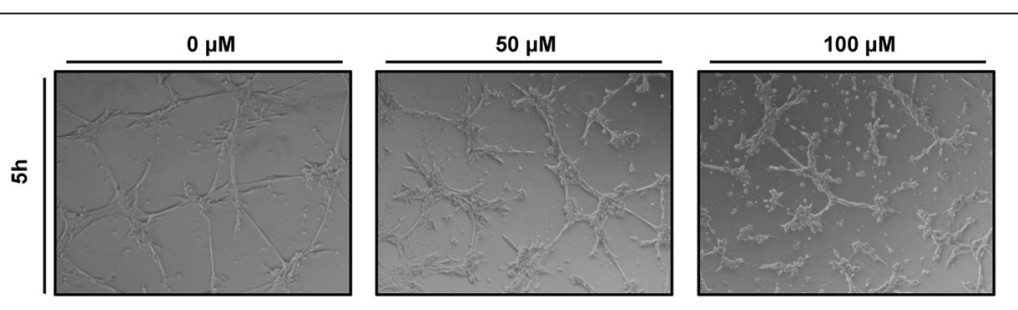

Fig. 6 Propranolol inhibits angiogenesis. Treatment with propranolol inhibits tubulogenesis of hemangioblastoma cells partially $(50 \mu \mathrm{M})$ or completely $(100 \mu \mathrm{M})$. (Magnification, 40X) 

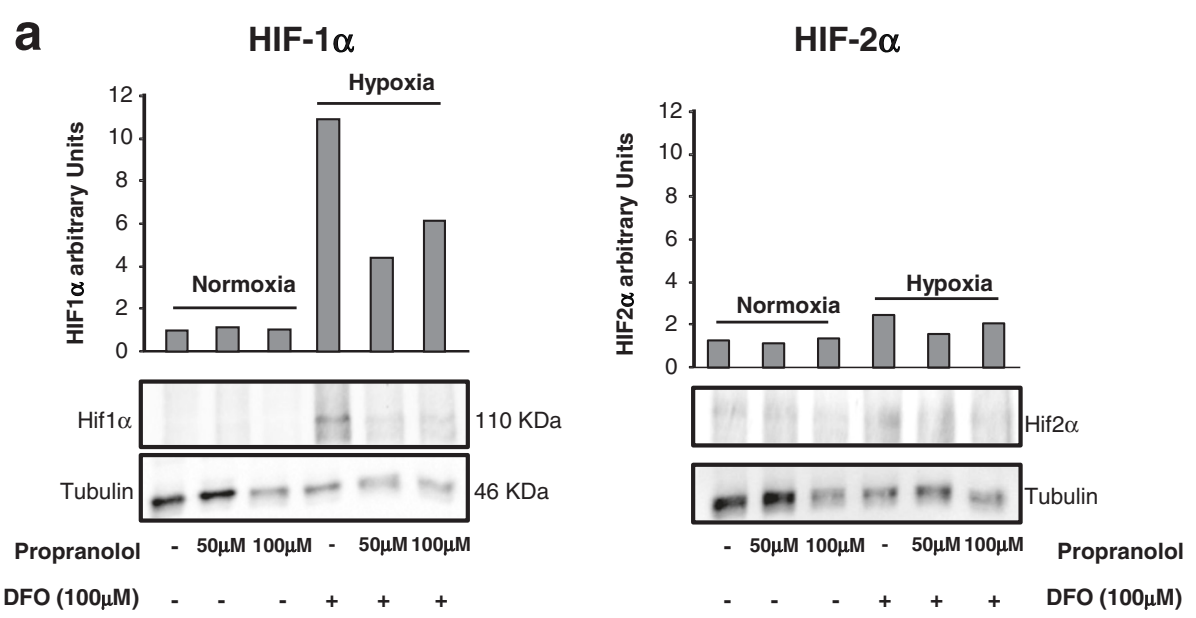

b
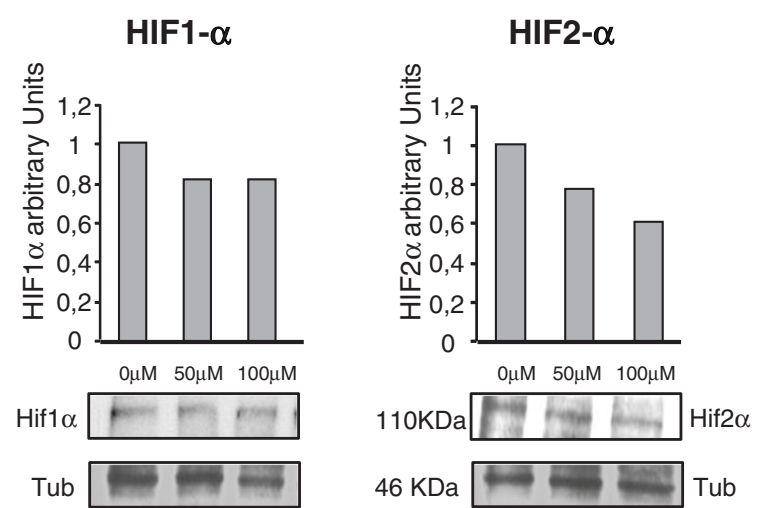

Fig. 7 HIF-1a and HIF-2a protein expression is decreased following propranolol treatment. a Western blot assays were performed on lysates from 9XHRE HeLa cells. In agreement with luciferase assays, there were no differences in HIF-1a and HIF-2a protein levels between the different propranolol treatments under normoxia. After DFO treatment (simulating hypoxia), levels of both proteins increased. When propranolol was added to the cells, HIF-1a and HIF-2a levels decreased. $\mathbf{b}$ Western blot analysis was performed on lysates from hemangioblastoma cells treated with 50 and $100 \mu \mathrm{M}$ propranolol for 24 h; HIF-1a and HIF-2a levels were reduced. $\gamma$-Tubulin was used as loading control

On the other hand, the article by Langley and Pope is essentially theoretical and not evidence-driven, and includes data from small studies in healthy adults.

Interestingly enough, all the HIF target genes, including among others, VEGF, MMPs, EPO or FGF, are absolutely necessary for the survival and progression of tumors in general, and for hemangioblastomas in particular. Hemangioblastomas are complex tumors consisting of different cellular types, with stromal (undifferentiated mesenchymal cells) and endothelial cells as the main components. Thus being so, propranolol might be able to stop vascular dependent growth of hemangioblastomas [2, 34].

In the present work, we have shown that propranolol downregulates HIF-1 targets. In fact, propranolol inhibited HIF-dependent transcription in a 9xHRE HeLa reporter cell line (Fig. 1) and the crucial gene targets for hemangioblastoma survival, such as VEGF, EPO and SOX2 (Fig. 2). EPO has been reported to be active in hemangioblastoma tumorlets of VHL patient [35-37], and according to Fig. 2a its expression was reduced by almost half in the presence of propranolol. On the other hand, VEGF was shown to be downregulated at the transcriptional level (Fig. 2a), but also as protein secreted into the culture supernatants of different hemangioblastomas cultivated in vitro (Fig. 2b). Moreover, the impaired angiogenesis of hemangioblastomas in matrigel is shown in Fig. 6, where the tubular network of untreated cells remained with unclosed cells at an intermediate dose of propranolol, and its formation was prevented at the highest propranolol dose. This is in agreement with the results obtained by Albiñana et al. (2012) where propranolol precluded the tube formation of treating EOMA and human endothelial cells at the highest dose.

Hemangioblastoma tissue is composed of neoplastic stromal cells and abundant reactive vascular cells [19, 24, 38]. VHL-deficient tumor cells have hemangioblastic differentiation capacity $[39,40]$. Stromal cells are undifferentiated cells of mesenchymal nature, where SOX-2 master stemness marker is expressed as a HIF- $2 \alpha$ target. Thus, we 
explored the expression of SOX-2 in hemangioblastoma before and after propranolol treatment, and SOX-2 levels were also significantly decreased by propranolol (Fig. 2).

We established that propranolol decreased HIFdependent transcription in 9XHRE HeLa cells under hypoxia and in hemangioblastoma cells constitutively expressing HIF, as shown in Fig. 7a, the amounts of HIF1 $\alpha$ and HIF $2 \alpha$ protein under hypoxic conditions in HeLa cells were decreased by propranolol treatment. This fact was also tested in hemangioblastoma cells that were functionally hypoxic, as shown by the expression of HIF1 $\alpha$ and
HIF $2 \alpha$ under normal culture conditions. Western blotting demonstrated that both HIF- $1 \alpha$ and $2 \alpha$ were decreased by propranolol treatment at the protein level (Fig. B).

Next, we explored whether propranolol could interfere with proliferation and survival of hemangioblastoma cells. As HIF triggers the hypoxia gene program to maintain cell survival, the previous results suggested that propranolol also affected cell viability. In fact, Fig. 3 demonstrates that propranolol reduced the viability of HeLa cells under hypoxic conditions. The cause of death was determined to be apoptosis, as measured by the activity of caspases $3 / 7$,
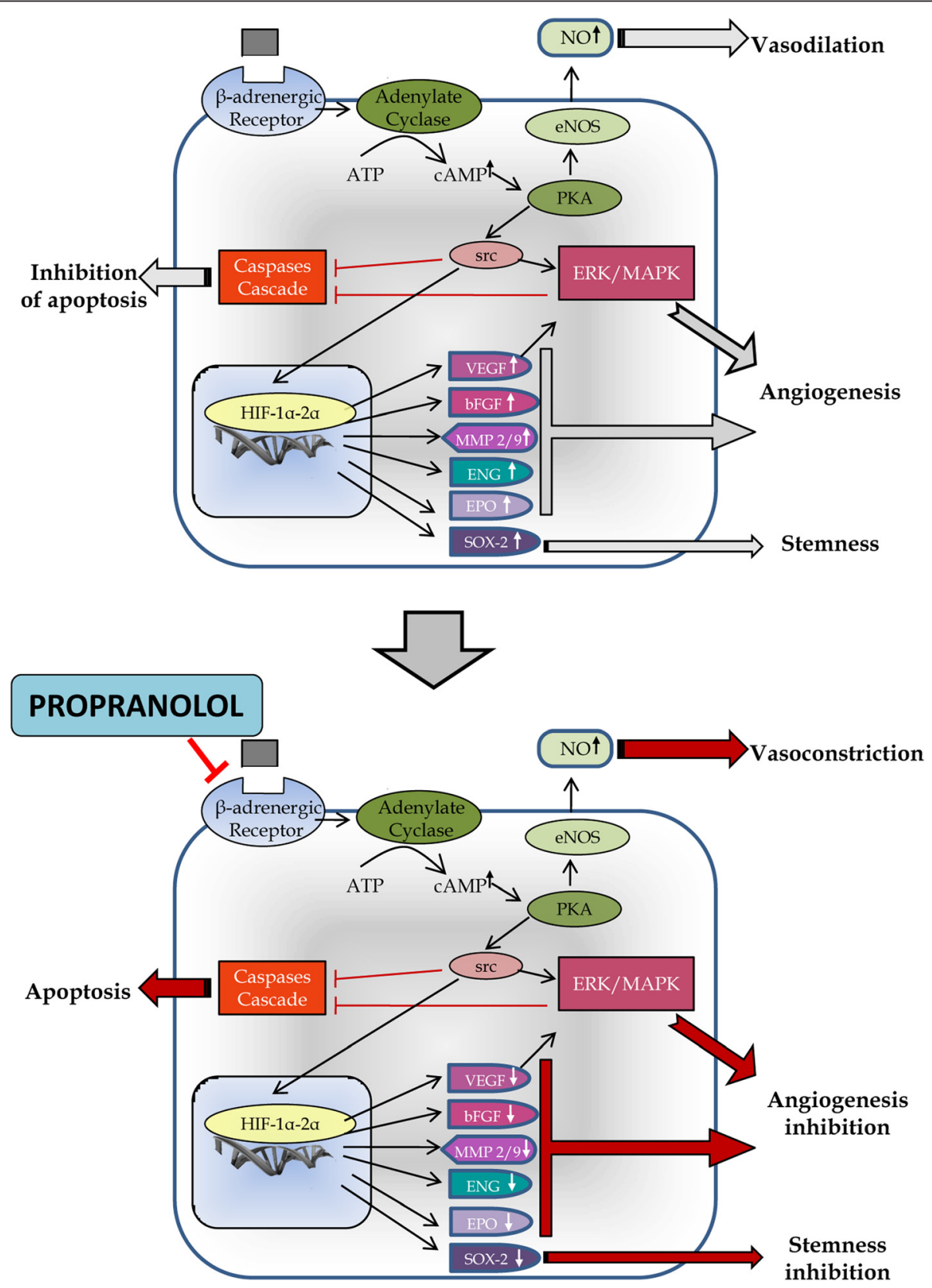

Fig. 8 Hypothetical model of propranolol mechanism of action 
which was increased by three-fold over untreated cells at the highest dose of propranolol. Interestingly, the same holds true when the viability and apoptosis of hemangioblastoma cells from different VHL patients were evaluated after propranolol treatment. Figure 4 shows that hemangioblastoma cell viability may drop by up to $50 \%$ after $48 \mathrm{~h}$, and that apoptosis is increased between 2.5- and 5-fold following $48 \mathrm{~h}$ of $100 \mu \mathrm{M}$ propranolol treatment.

Given these results, our assumption was that, if propranolol treatment was sustained in time, cells would disappear as is shown in Fig. 5 in hemangioblastoma cells. Notably, after $96 \mathrm{~h}$ at $100 \mu \mathrm{M}$ propranolol treatment, very few cells remained attached to the wells, and those that remained alive had an extremely thin and elongated shape, showing the appearance of apoptotic cells.

Altogether, the results suggest that propranolol first decreases HIF levels in hemangioblastoma cells, and in this way, the HIF targets are partially silenced/decreased. Consequently, in the absence of essential factors for survival, the tumor cells, stop dividing and die by apoptosis. A scheme showing the hypothetical mechanism of action of propranolol investigated in the present paper is presented in Fig. 8.

\section{Conclusions}

In conclusion, our results suggest that propranolol reduces the growth of HIF-dependent tumors, and may be a promising therapeutic drug to delay surgery in VHL patients.

\footnotetext{
Abbreviations

ALK1: Activin receptor like kinase 1; CNS: Central nervous system; DFO: Deferroxiamine; DMEM: Dulbecco's modified Eagle medium; EOMA: Mouse hemangioendothelioma edothelial cells; EPO: Erythropoietin; FBS: Fetal bovine serum; FGF: Fibroblast growth factor; HIF: Hypoxia inducible factor; HRE: Hypoxia responsive element; IH: Infantile hemangioma; MMP: Matrix metalloproteinases; pVHL: Von Hippel Lindau protein; RPMI: Roswell Park Memorial Institute; RT-PCR: Reverse transcription polymerase chain reaction; SDS-PAGE: Sodium dodecyl sulfatepolyacrylamide gel electrophoresis; SOX-2 or SRY-box 2: Sex-determining region Y-box; VEGF: Vascular endothelial growth factor; VHL: Von HippelLindau.
}

\section{Competing interests}

The authors declare that they have no competing interests.

\begin{abstract}
Authors' contributions
VA carried out the majority of the experimental work and writing of the manuscript. KVGH provided advice, co-direction of the main strategies and funding. TS and ABPM directed the experimental culture of VHL hemangioblastomas. GSH designed and performed the growth and characterization of hemangioblastoma primary explants. JMC performed the surgeries (neurosurgeon for VHL patients). LMB directed and coordinated the in vitro experiments, and the design and experimental approach strategies, and project fund provision and writing of the manuscript. All authors read and approved the final manuscript.
\end{abstract}

\section{Acknowledgements}

This work was supported by grants from Ministerio de Economia y Competitividad SAF2011-23475 and from Alianza VHL Spain\& Fundación Iberdrola to LMB. Virginia Albiñana was supported by Alianza VHL Spain,
Fundación Iberdrola and Fundación Divina Pastora. We are grateful to the patients who participated in our research, and we thank the physicians Pablo de Andrés and Delia Viñas (Fundación Jiménez Díaz, Madrid, Spain) who participated in the collection of patient samples and data and Dr Blanca Carrión as scientific collaborator in obtaining primary cultures of CNS hemangioblastoma.

\section{Author details}

'Centro de Investigaciones Biológicas, CSIC, Madrid, Spain. ${ }^{2}$ SSCC del Servicio de Salud de Castilla-La Mancha (SESCAM), Toledo, Spain. ${ }^{3}$ Unidad de Investigación, Complejo Universitario Hospital Albacete, Albacete, Spain. ${ }^{4}$ Centro de Investigación Biomédica en Red de Enfermedades Raras (CIBERER), Madrid, Spain. ${ }^{5}$ Servicio de Neurocirugía, Fundación Jiménez Díaz, Madrid, Spain.

Received: 22 May 2015 Accepted: 16 September 2015

Published online: 22 September 2015

\section{References}

1. Maher ER, Neumann HP, Richard S. Von Hippel-Lindau disease: a clinical and scientific review. Eur J Hum Genet. 2011;19:617-23.

2. Richard S, Gardie B, Couvé S, Gad S. Von Hippel-Lindau: how a rare disease illuminates cancer biology. Semin Cancer Biol. 2013;23(1):26-37.

3. Kaelin Jr WG. Molecular basis of the VHL hereditary cancer syndrome. Nat Rev Cancer. 2002;2(9):673-82.

4. Kaelin Jr WG. The von Hippel-Lindau tumor suppressor protein: $\mathrm{O} 2$ sensing and cancer. Nat Rev Cancer. 2008;8(11):865-73.

5. Bausch B, Jilg C, Gläsker S, Vortmeyer A, Lützen N, Anton A, et al. Renal cancer in von Hippel-Lindau disease and related syndromes. Nat Rev Nephrol. 2013;9(9):529-38.

6. Vortmeyer AO, Falke EA, Gläsker S, Li J, Oldfield EH. Nervous system involvement in von Hippel-Lindau disease: pathology and mechanisms. Acta Neuropathol. 2013;125(3):333-50.

7. Gläsker S, Bender BU, Apel TW, van Velthoven V, Mulligan LM, Zentner J, et al. Reconsideration of biallelic inactivation of the VHL tumor suppressor gene in hemangioblastomas of the central nervous system. J Neurol Neurosurg Psychiatry. 2001;70(5):644-8.

8. Bader HL, Hsu T. Systemic VHL gene functions and the VHL disease. FEBS Lett. 2012;586(11):1562-9.

9. Haddad NM, Cavallerano JD, Silva PS. Von hippel-lindau disease: a genetic and clinical review. Semin Ophthalmol. 2013;28(5-6):377-8.

10. Kassardjian CD, Macdonald RL, Munoz DG. Hemangioblastomas in the elderly: epidemiology and clinical characteristics. J Clin Neurosci. 2014;21(7):1205-8.

11. Sanchez-Carpintero I, Ruiz-Rodrig R, Lopez-Gutierrez JC. propranolol in the treatment of infantile hemangioma: clinical effectiveness, risks, and recommendations. Actas Dermosifiliogr. 2011;102:766-79.

12. Léauté-Labrèze C, Hoeger P, Mazereeuw-Hautier J, Guibaud L, Baselga E, Posiunas $\mathrm{G}$, et al. A randomized, controlled trial of oral propranolol in infantile hemangioma. N Engl J Med. 2015;372(8):735-46.

13. Storch $\mathrm{CH}$, Hoeger PH. propranolol for infantile haemangiomas: insights into the molecular mechanisms of action. Br J Dermatol. 2010;163:269-74.

14. Lamy S, Lachambre MP, Lord-Dufour S, Béliveau R. propranolol suppresses angiogenesis in vitro: inhibition of proliferation, migration, and differentiation of endothelial cells. Vasc Pharmacol. 2010;53:200-8.

15. Leaute-Labreze C, de la Dumas Roque E, Hubiche T, Boralevi F, Thambo JB, Taïeb A. propranolol for severe hemangiomas of infancy. N Engl J Med. 2008;358:2649-51.

16. Albiñana V, Recio-Poveda L, Zarrabeitia R, Bernabéu C, Botella LM. propranolol as antiangiogenic candidate for the therapy of hereditary haemorrhagic telangiectasia. Thromb Haemost. 2012;108(1):41-53.

17. Ponnaluri VK, Vavilala DT, Prakash S, Mukherji M. Hypoxia mediated expression of stem cell markers in VHL-associated hemangioblastomas. Biochem Biophys Res Commun. 2013;438(1):71-7.

18. Flamme I, Krieg M, Plate KH. Up-regulation of vascular endothelial growth factor in stromal cells of hemangioblastomas is correlated with up-regulation of the transcription factor HRF/HIF-2alpha. Am J Pathol. 1998;153(1):25-9.

19. Gläsker S, Smith J, Raffeld M, Li J, Oldfield EH, Vortmeyer AO. VHL-deficient vasculogenesis in hemangioblastoma. Exp Mol Pathol. 2014;96(2):162-7.

20. Sommers Smith SK, Smith DM. Beta blockade induces apoptosis in cultured capillary endothelial cells. In Vitro Cell Dev Biol Anim. 2002;38:298-304. 
21. Maher ER, Yates JR, Harries R, Benjamin C, Harris R, Moore AT, et al. Clinical features and natural history of von Hippel-Lindau disease. Q J Med. 1990;77(283):1151-63.

22. Lonser RR, Glenn GM, Walther M, Chew EY, Libutti SK, Linehan WM, et al. Von Hippel-Lindau disease. Lancet. 2003;361(9374):2059-67.

23. Knudson Jr AG. Mutation and cancer: statistical study of retinoblastoma. Proc Natl Acad Sci U S A. 1971;68(4):820-3.

24. Vortmeyer AO, Gnarra JR, Emmert-Buck MR, Katz D, Linehan WM, Oldfield $\mathrm{EH}$, et al. Von Hippel-Lindau gene deletion detected in the stromal cell component of a cerebellar hemangioblastoma associated with von Hippel-Lindau disease. Hum Pathol. 1997;28(5):540-3.

25. Semenza GL. Regulation of metabolism by hypoxia-inducible factor 1 . Cold Spring Harb Symp Quant Biol. 2011;76:347-53.

26. Ke Q, Costa M. Hypoxia-inducible factor-1 (HIF-1). Mol Pharmacol, 2006;70(5):1469-80.

27. Manalo DJ, Rowan A, Lavoie T, Natarajan L, Kelly BD, Ye SQ, et al. Transcriptional regulation of vascular endothelial cell responses to hypoxia by HIF-1. Blood. 2005;105(2):659-69.

28. Périgny M, Hammel P, Corcos O, Larochelle O, Giraud S, Richard S, et al. Pancreatic endocrine microadenomatosis in patients with von Hippel-Lindau disease: characterization by VHL/HIF pathway proteins expression. Am I Surg Pathol. 2009;33(5):739-48.

29. England RW, Hardy KL, Kitajewski AM, Wong A, Kitajewski JK, Shawber CJ, et al. propranolol promotes accelerated and dysregulated adipogenesis in hemangioma stem cells. Ann Plast Surg. 2014;73 Suppl 1:S119-24.

30. Wong A, Hardy KL, Kitajewski AM, Shawber CJ, Kitajewski JK, Wu JK. Propranolol accelerates adipogenesis in hemangioma stem cells and causes apoptosis of hemangioma endothelial cells. Plast Reconstr Surg. 2012;130(5):1012-21.

31. Langley A, Pope E. Propranolol and central nervous system function: potential implications for paediatric patients with infantile haemangiomas. Br J Dermatol. 2015;172(1):13-23.

32. Tozzi A. Oral Propranolol for Infantile Hemangioma. N Engl J Med. 2015;373(3):284.

33. Léauté-Labrèze C, Voisard JJ, Moore N. Oral Propranolol for Infantile Hemangioma. N Engl J Med. 2015;373(3):284-5.

34. Wizigmann-Voos S, Plate KH. Pathology, genetics and cell biology of hemangioblastomas. Histol Histopathol. 1996;11(4):1049-61.

35. Ang SO, Chen H, Gordeuk VR, Sergueeva Al, Polyakova LA, Miasnikova GY, et al. Endemic polycythemia in Russia: mutation in the VHL gene. Blood Cells Mol Dis. 2002;28(1):57-62.

36. Liu E, Percy MJ, Amos Cl, Guan Y, Shete S, Stockton DW, et al. The worldwide distribution of the VHL 598C $>$ T mutation indicates a single founding event. Blood. 2004;103(5):1937-40.

37. Franke K, Gassmann M, Wielockx B. Erythrocytosis: the HIF pathway in control. Blood. 2013;122(7):1122-8.

38. Lee JY, Dong SM, Park WS, Yoo NJ, Kim CS, Jang JJ, et al. Loss of heterozygosity and somatic mutations of the VHL tumor suppressor gene in sporadic cerebellar hemangioblastomas. Cancer Res. 1998;58(3):504-8.

39. Shively SB, Beltaifa S, Gehrs B, Duong H, Smith J, Edwards NA, et al. Protracted haemangioblastic proliferation and differentiation in von Hippel-Lindau disease. J Pathol. 2008;216(4):514-20.

40. Vortmeyer AO, Tran MG, Zeng W, Gläsker S, Riley C, Tsokos M, et al. Evolution of VHL tumourigenesis in nerve root tissue. J Pathol. 2006;210(3):374-82.

\section{Submit your next manuscript to BioMed Central and take full advantage of:}

- Convenient online submission

- Thorough peer review

- No space constraints or color figure charges

- Immediate publication on acceptance

- Inclusion in PubMed, CAS, Scopus and Google Scholar

- Research which is freely available for redistribution 